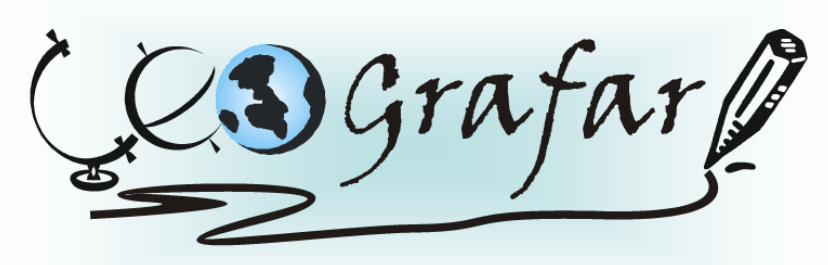

Revista Eletrônica do Programa de Pós-Graduação em Geografia - UFPR

\title{
O PROGRAMA NACIONAL DE DESENVOLVIMENTO SUSTENTÁVEL DOS TERRITÓRIOS RURAIS (PRONAT) NO VALE DO RIBEIRA (PR) ${ }^{1}$
}

\author{
PAULA CHAGAS FRANCIS LEAL ${ }^{2}$
}

\begin{abstract}
RESUMO
Esse artigo aborda o Programa Nacional de Desenvolvimento Sustentável dos Territórios Rurais (PRONAT), instituído pelo governo de Luiz Inácio Lula da Silva no ano de 2003, com o intuito de dotar os Territórios Rurais homologados pela Secretaria de Desenvolvimento Territorial (SDT) de melhores infra-estruturas e serviços. A análise do programa torna-se fundamental para verificar qual é o tipo de território que vem sendo criado por essa política pública estabelecida pela secretaria. O recorte espacial da pesquisa faz referência aos municípios rurais que integram o atual Vale do Ribeira (PR), que desde o ano de 2003 até aos dias de hoje desenvolvem projetos territoriais na busca por uma melhor inserção econômica e social dentro do Estado. Desde tempos os municípios rurais deste local têm recebido incentivos por parte do governo, entretanto ainda prevalecem relações pautadas num desenvolvimento com vistas ao controle social. Nota-se que esses projetos não resultaram em um desenvolvimento propriamente dito, ou seja, são decorrência ainda de uma política pública que necessita ser mais bem estruturada para de fato atender à população do campo.
\end{abstract}

Palavras-chave: PRONAT. Vale do Ribeira (PR). Desenvolvimento rural.

\footnotetext{
${ }^{1}$ Este artigo é resultado da Dissertação de Mestrado apresentada ao curso de Pós-Graduação do Departamento de Geografia da Universidade Federal do Paraná (UFPR) no ano de 2010.

${ }^{2}$ Mestre em Geografia - Universidade Federal do Paraná; e-mail: paulinha geo12@hotmail.com
} 


\title{
NATIONAL PROGRAM OF SUSTAINABLE DEVELOPMENT OF RURAL TERRITORIES IN VALE DO RIBEIRA (PARANÁ STATE)
}

\begin{abstract}
This article approaches a Brazilian territorial project named Programa Nacional de Desenvolvimento Sustentável dos Territórios Rurais (National Program of Sustainable Development of Rural Territories) that was brought up in 2003 by the Government of president Luiz Inácio Lula da Silva. The Program's main goal is to provide better infrastructure and services to the Rural Territories homologated by the Secretaria de Desenvolvimento Territorial (Territorial Development Office). It is fundamental that an analysis of the program be done in order to verify what sort of territory has been crafted by this public policy established by the following Office. The spatial range of this research englobes the rural municipalities within Vale do Ribeira (Ribeira Valley), in Paraná State. Such towns develop territorial projects in order to achieve a better economical insertion in and out of the State since 2003. It has been a while since some rural municipalities have been granted with government incentive in order to develop, however development relations based on social control still remain present. It is clear that these projects have not attained such development, which means that these public policies still need to be better structured in order to truly assist the rural area population.
\end{abstract}

Key words: PRONAT. Vale do Ribeira. Rural (PR) Development. 


\section{INTRODUÇÃO}

Este artigo é resultado de uma pesquisa realizada em 2010 no Vale do Ribeira (PR). O foco de análise é o Programa Nacional de Desenvolvimento Sustentável dos Territórios Rurais (PRONAT) instituído no governo de Luiz Inácio Lula da Silva para ofertar melhores infra-estruturas e serviços aos municípios rurais que apresentam baixos Índices de Desenvolvimento Humano Municipal (IDH-M), proporcionando assim melhorias sociais e econômicas.

Para compreender o programa foram realizados trabalhos de pesquisa que se dividiram em três etapas; na primeira para avaliar o PRONAT em seus elementos conceituais foi feita uma revisão teórica dos conceitos de território, território rural e desenvolvimento territorial rural, com base em trabalhos já elaborados sobre o tema.

Por conseguinte foi feito um levantamento de dados priorizando $o$ acesso às informações secundárias. Para analisar as diretrizes do programa foram consultados os documentos institucionais oficiais do Ministério do Desenvolvimento Agrário (MDA) e da Secretaria de Desenvolvimento Territorial (SDT), divulgados por meio eletrônico.

Com o intuito de obter informações empíricas primárias in loco por último foram realizados os trabalhos de campo. No primeiro, foi feita uma entrevista com o articulador do Vale do Ribeira (PR), com base em um questionário com questões subjetivas para obter informações sobre os municípios e compreender como se encontra a demanda dos recursos públicos do PRONAT.

Também foram feitas duas entrevistas na Secretaria da Agricultura e do Abastecimento do Paraná (SEAB) de Curitiba (PR); a primeira, com o secretario executivo do Conselho Estadual de Desenvolvimento Rural e Agricultura Familiar (entrevistado A) e a segunda, com o chefe da divisão de desenvolvimento rural (entrevistado B).

Esta secretaria disponibilizou a relação de projetos elaborados para o Vale do Ribeira remetidos ao MDA/SDT do período de 2003 a 2008 e o Plano de Desenvolvimento Rural do Território Rural atualizado, que permitiu compreender a proposta do programa para o campo brasileiro.

Com outro questionário norteador foi realizada na Empresa de Extensão e Assistência Técnica do Estado do Paraná (EMATER) uma entrevista com a gerente 
territorial do Vale do Ribeira. Além das informações referentes aos municípios, foi possível diagnosticar as atribuições dessa instituição e os resultados da aplicação dos recursos do PRONAT.

Por fim, coletaram-se informações de assuntos correlacionados ao desenvolvimento do território no "Encontro do Conselho Gestor do Fórum Territorial Vale do Ribeira Paraná" de 2009, através da tomada de opiniões com os representantes do fórum territorial e atores sociais envolvidos na elaboração dos projetos; tais como membros da SEAB, da EMATER, da Cooperativa de Crédito Rural com Interação Solidária da Agricultura Familiar (CRESOL), o próprio articulador e agricultores familiares residentes nos municípios.

Considera-se importante estabelecer uma reflexão acerca da operacionalização do PRONAT, para averiguar que tipo de espaço vem sendo definido como "território" no âmbito do programa. Do mesmo modo, é de grande valia verificar se os processos de desenvolvimento propostos para o Vale do Ribeira estão sendo coerentes com as múltiplas dimensionalidades do rural estabelecidas pelo MDA/SDT.

Sendo o campo brasileiro palco de disparidades regionais, a análise do PRONAT faz-se necessária para verificar se realmente há resultados em termos de melhoria das condições de vida das populações rurais de municípios pobres possibilitando de fato o desenvolvimento.

\section{LOCALIZAÇÃO DA ÁREA DE ESTUDO}

O Vale do Ribeira comporta parte do território paulista e paranaense, estando estruturado a partir da Bacia Hidrográfica do Ribeira do Iguape, indo desde o litoral sul de São Paulo até o litoral norte do Paraná. São cerca de $30.000 \mathrm{Km}^{2}$ com uma população de aproximadamente 720.000 habitantes distribuídos num total de 38 municípios, sendo respectivamente 23 do Estado de São Paulo e 15 do Paraná (IPARDES, 2003).

Para avaliar o programa foram selecionados os municípios que integram o atual Vale do Ribeira da porção paranaense, os quais são: Adrianópolis, Bocaiúva do Sul, Cerro Azul, Doutor Ulysses, Itaperuçu, Rio Branco do Sul e Tunas do Paraná, destacados no mapa 1. 


\section{LOCALIZAÇÃO DA ÁREA DE ESTUDO}
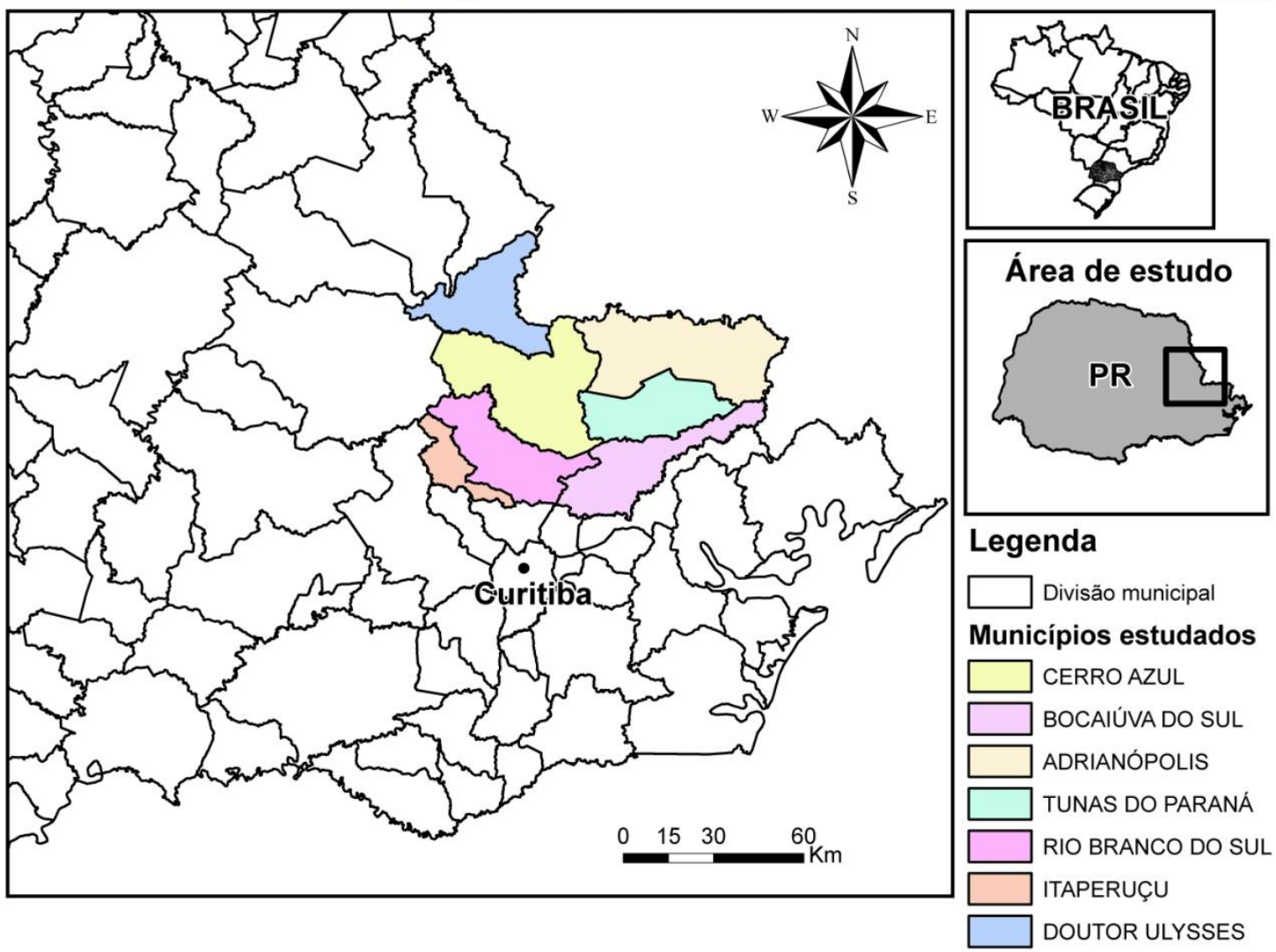

MAPA 01 - LOCALIZAÇÃO DA ÁREA DE ESTUDO

Nota: Mapa elaborado com o software ArcGIS 9.0 (ESRI, 2001).

É fato que a demanda de recursos públicos ofertados pelo PRONAT tem por objetivo minimizar com os problemas sociais e econômicos desses sete municípios; porém, mesmo integrados na Região Metropolitana de Curitiba, constituem-se ainda num enclave de estagnação econômica e apresentam um baixo desenvolvimento social.

É importante frisar que desde 2003 o governo federal adota o conceito de território como diretriz de política pública, possibilitando que os municípios rurais do Vale do Ribeira disponham de recursos financeiros para investir em melhores infraestruturas e serviços. Em termos de política pública o PRONAT visa substituir o tradicional enfoque setorial por ações centradas no desenvolvimento desses municípios rurais; um desenvolvimento que se trata ainda de um grande desafio. 


\title{
3 AS POLÍTICAS PÚBLICAS FORMULADAS PARA O CAMPO BRASILEIRO
}

A análise de uma série de documentos institucionais elaborados pelo MDA e a SDT faz crer que a proposta do PRONAT adota o conceito de território para tão somente realizar a gestão de planejamentos institucionais, privilegiando uma conotação claramente normativa da abordagem territorial. Porém, esse tipo de abordagem ofusca a existência de um controle social e de reprodução do capital, ou seja, a dimensão territorial proposta pelo desenvolvimento não ocorre.

Dentre esses diversos documentos destaca-se o "Plano Territorial de Desenvolvimento Rural Sustentável" (MDA, 2005), neste o território é compreendido como um:

\begin{abstract}
Espaço que sintetiza e materializa num determinado espaço geográfico um processo social, econômico, ecológico e cultural complexo, em interação com outros espaços diferenciados. O território não se limita a uma simples demarcação geográfica ou político-administrativa, traçada de forma mais ou menos arbitrária ou como reflexo de interesses políticos, mas só existe enquanto articulação e relação com outros espaços ou formações socioculturais (BUARQUE, apud MDA, 2005, p. 11).
\end{abstract}

Observa-se uma definição muito bem formulada ao destacar a necessidade de valorizar o caráter multidimensional do território; tais como o ambiente, a economia, a sociedade, a cultura, a política e as instituições. Entretanto, a realidade demonstra que os territórios rurais abarcam um conjunto de municípios "com diferentes atividades produtivas, com diversas potencialidades, com uma população que apresenta características, necessidades e demandas múltiplas" (MONTENEGRO GÓMEZ, 2006, p. 90).

Correlacionado a isso nota-se que questões como o controle, o ordenamento e a gestão de espaços têm sido temas centrais na discussão sobre o conceito de território pelo governo. Este para atender aos seus objetivos estabelece um conjunto de relações de poder, que resultam no domínio de determinados espaços configurando um território, uma vez que "todo espaço definido e delimitado por e a partir de relações de poder é um território" (SOUZA, 2003, p. 78). Todavia, a seguinte questão proposta por Souza (2003) não pode ser negligenciada:

O verdadeiro Leitmotiv é o seguinte: quem domina ou influencia e como domina ou influencia esse espaço? Este Leitmotiv traz embutida, ao menos de um ponto de vista não interessado em escamotear conflitos e contradições sociais, a seguinte questão inseparável, uma vez que o 
território é essencialmente um instrumento de exercício de poder: quem domina ou influencia quem nesse espaço, e como?(SOUZA, 2003, p. 79).

Não há como negar que a adoção de políticas públicas para o meio rural seja um fato; no entanto, estas acabam por traduzir "através de seu processo de elaboração e implantação e, sobretudo, pelos seus resultados, formas de exercício do poder político" (BEDIN, 2005, p. 25) que se entrelaçam através de um conjunto de relações sociais e envolvem vários atores sociais.

No Vale do Ribeira constata-se que há um nítido exercício deste poder. O organograma 1 permite visualizar que várias são as entidades que vem dando efetivo apoio ao local, cada qual com suas especificidades. No entanto, todas perpassam pelo MDA e a SDT, instâncias superiores que materializam suas ações utilizando seus recursos financeiros e o poder que detêm para ordenar os municípios, resultando num conjunto de programas e projetos para o local.

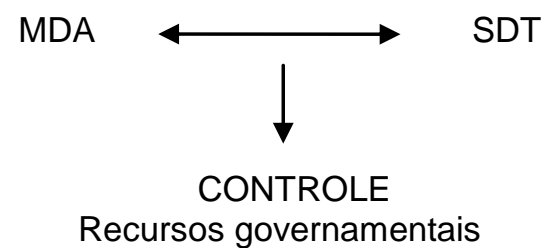

Relações espaço - poder institucionalizadas

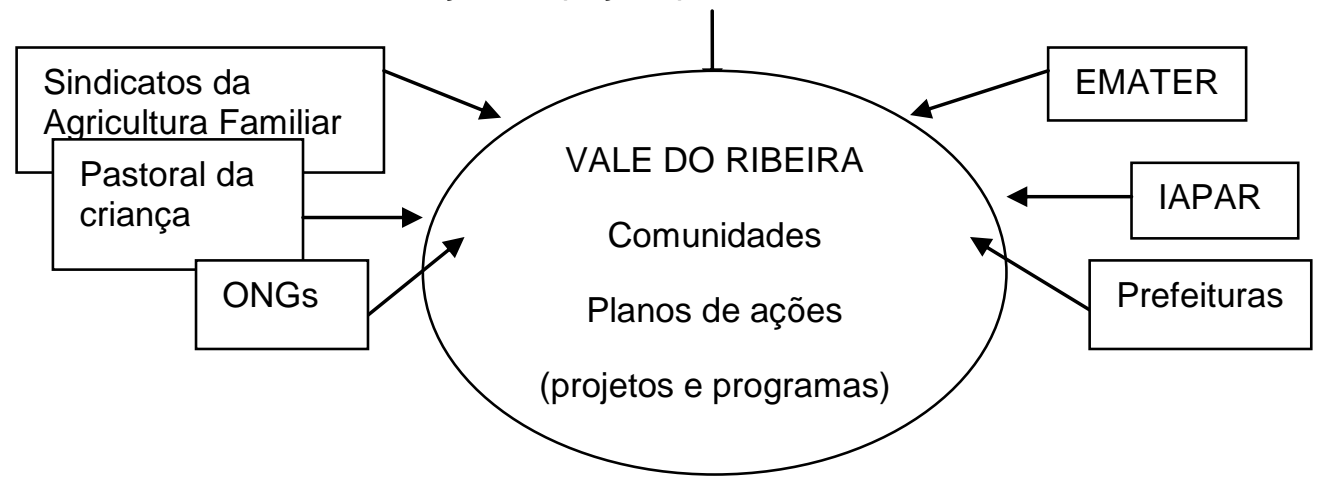

\section{ORGANOGRAMA 1 - ATUAÇÕES NO VALE DO RIBEIRA (PR)}

FONTE: O autor (2009)

Nota: dados obtidos do fórum do desenvolvimento territorial do Vale do Ribeira (2006) realizado em $5 / 9 / 2009$.

O organograma permite afirmar, como bem exposto por Fernandes (2008, p. 5), que se convive com distintos tipos de territórios produtores e produzidos por diferentes relações sociais, desde instituições, organizações, até sujeitos sociais, 
cada qual elabora o seu território e o conteúdo do mesmo, desde que detenha poder político para mantê-lo.

Para o autor são as instituições que compõem o Estado, bem como partidos, sindicatos, igrejas, fundações, cooperativas, empresas, movimentos e organizações não governamentais (ONGs), que estabelecem espaços e territórios no interior do próprio território do Estado, perfazendo assim distintas soberanias.

No que diz respeito às instituições governamentais, observa-se que essas ao adotarem o conceito de território atendem aos interesses de parcela da população, expressando assim:

Sua mais cara propriedade: as relações de poder. Por essa razão, parece nos que a multidimensionalidade, embora presente na significação do conceito de território em muitos artigos e documentos, não se realiza, porque implicaria na socialização das tomadas de decisão (FERNANDES, 2008, p. 4)

Porém, como bem mencionado por Schneider (2004) o uso normativo do conceito de território requer ponderações, não se pode adaptar pura e simplesmente o sentido conceitual e analítico do termo para fins normativos e operacionais, é necessário que se façam mediações e adequações. O autor enfatiza que os usuários não-acadêmicos precisam deixar de lado as questões teóricas e heurísticas e devem utilizar o conceito de território e mesmo da abordagem territorial na perspectiva do desenvolvimento rural, conferindo assim uma utilidade normativa e prática.

Considera-se que se os usuários não-acadêmicos deixarem de lado as questões teóricas e heurísticas o uso do conceito perderá a sua essência, passando a ser realmente apropriado para fins apenas práticos e normativos, como uma ferramenta operacional. Deste modo, concorda-se com Souza (2003) que:

$\mathrm{Na}$ verdade, o território não é simplesmente uma variável estratégica em sentido político-militar; o uso e o controle do território, da mesma maneira que a repartição real de poder, devem ser elevados a um plano de grande relevância também quando da formulação de estratégias de desenvolvimento sócio-espacial em sentido amplo, não meramente econômico- capitalístico, isto é, que contribuam para uma maior justiça social e não se limitem a clamar por crescimento econômico e modernização tecnológica (SOUZA, 2003, p. 100). 
Romper com esses valores conservadores é necessário, para que de fato o uso do conceito de território possa ser incorporado aos ideais de um verdadeiro desenvolvimento, sem que haja distorções nem regalias para quem quer que seja (SOUZA, 2003, p. 99).

O PRONAT é um exemplo claro de como o discurso do desenvolvimento tem sido moldado, elaborado como uma política pública para solucionar com os problemas sociais e econômicos, o programa vem transferindo as responsabilidades da aplicação dos recursos públicos das esferas federais para as municipais, gerando novas configurações de relações descentralizadas e estimulando assim, as ações entre os diversos atores sociais dos territórios rurais (HESPANHOL, 2007, p. 275).

$\mathrm{Na}$ atualidade para promover esse tipo de desenvolvimento, o documento Referências para uma Estratégia de Desenvolvimento Rural Sustentável no Brasil (2005) relata ser necessário contemplar medidas que:

Objetivem a melhoria contínua da qualidade de vida do conjunto da população do território, não apenas de parte dela. Portanto, é indispensável que haja uma forte articulação de políticas públicas entre si, nos diversos níveis de governo, com as iniciativas da sociedade, do setor privado dos diversos ramos de atividades (MDA, 2005, p. 05).

É nesse sentido que a partir de 2003 adotam-se políticas públicas descentralizadas de forma mais contundente, as quais vêm dando atribuições aos territórios rurais em que atores sociais, através de entidades municipais, passam a ter o papel de gerenciar a aplicação dos recursos públicos que lhes são ofertados.

Entretanto, apenas transferir a responsabilidade de atribuições de uma esfera para outra não basta, tanto a participação do governo federal e dos estaduais "deve ser de caráter contratual e não pode se restringir a um repasse de recursos financeiros" (VEIGA, 2001, p. 19).

O meio rural está diante de ponderações que não devem ser deixadas a margem. A própria problemática do uso do conceito de território e mesmo da abordagem territorial para o desenvolvimento rural requer avaliações. Que tipo de desenvolvimento se propõe a fazer? Algo utópico a ser alcançado, em nada adianta desenvolver uma dada localidade, se nessa perpassam dificuldades que devem ser solucionadas num primeiro momento, sendo assim: 
É altamente significativo- e lamentável- que uma noção tão fundamental quanto à de desenvolvimento tenha sido reduzida, ao se transformar (...) em uma idéia tão distante das necessidades mais elementares e do quotidiano dos homens e mulheres comuns (SOUZA, 2003, p. 101).

Faz-se necessário criar oportunidades reais de políticas públicas descentralizadas. Foi a partir de 2003 que a SDT passou a ser a responsável pelos repasses dos recursos do PRONAT, até então feito pela antiga linha do Programa Nacional de Fortalecimento da Agricultura Familiar (PRONAF), denominada por Infra-Estrutura e Serviços Municipais, que era de responsabilidade da Secretaria da Agricultura Familiar (SAF). Com a adoção ao programa pela SDT as especificidades local/regional foram consideradas ao menos em tese na formulação desta política pública (HESPANHOL, 2007, p. 275).

Segundo o documento "Plano Territorial de Desenvolvimento Rural Sustentável guia para o planejamento" (2005) a incumbência dada à SDT é a de estimular e coordenar os projetos de desenvolvimento dos territórios rurais, tendo a missão de "apoiar a organização e o fortalecimento institucional dos atores sociais locais, na gestão participativa do desenvolvimento sustentável dos territórios rurais" (MDA, 2005, p. 14).

$\mathrm{Na}$ atualidade, em nível local há espaços para que se promovam iniciativas de interação entre a sociedade civil e o governo, chamados de colegiados de desenvolvimento territorial rural sustentável; sendo que, são participações essencias na tomada de decisões as entidades públicas, tais como: prefeituras municipais, sindicatos rurais, ONGs, associações comunitárias e os fóruns municipais.

Esses colegiados são compostos por atores sociais e gestores públicos a nível federal, estadual e municipal e por instâncias de gestão do desenvolvimento territorial. No entanto, nota-se que há ainda uma carência de articulação entre esses próprios níveis ao se transferir as responsabilidades para agricultores familiares e suas respectivas organizações de forma descentralizada.

Apesar de ainda num estágio embrionário, há a participação da sociedade civil pelo Vale do Ribeira. Porém, com problemas que não podem ser negligenciados; ao se repassar a responsabilidade para seus atores sociais nem todos estão devidamente preparados para desempenhar as ações em suas localidades, visto que encontram dificuldades em materializá-las pela existência de limites operacionais, por exemplo. 
Após essa análise de como vem se delineando as políticas públicas para o meio rural será apresentada a realidade pela qual o Vale do Ribeira tem se deparado ao receber os recursos do PRONAT. Este território rural apresenta um conjunto de municípios que se destacam no Estado do Paraná por possuírem inúmeros problemas sociais e econômicos a serem superados.

Antes é importante frisar que o local está diante de forças de poder perfazendo um território. O Leitmotiv citado por Souza (2003, p. 79), "[...] quem domina ou influencia e como domina ou influencia esse espaço [...]", faz crer que pelos municípios há vários tipos de influências; sendo que duas se destacam, a primeira da SDT que exerce domínio sobre o território através da elaboração e implantação dos projetos territoriais; e a segunda, referente ao poder que se perfaz na figura de alguns prefeitos dos municípios.

Da mesma maneira presenciam outras formas de poder, visto que há a existência de diversas instituições que atuam no local; todavia, se tratam de parcerias um tanto quanto inusitadas, que vão desde os níveis federais, estaduais até o municipal.

Em nível federal, há instâncias tais como o MDA, a SDT e a Universidade Federal do Paraná (UFPR); já no estadual presenciam-se instituições como a SEAB e a EMATER; e por fim, no nível municipal, estão as prefeituras, a sociedade civil e as ONGs.

Convém destacar à ação sindical pelos municípios, o sindicato de Bocaiúva do Sul é o único que apresenta uma forte atuação; sendo, o mais ativo, os restantes "são um tanto quanto complicados", como enfatizado pelo articulador do território.

No que diz respeito à ação das prefeituras, a EMATER ressalta que essas são consideradas as principais parceiras para o apoio técnico da assistência técnica e extensão rural. De acordo com o articulador projetos oriundos de ONGs e universidades como a UFPR tem contribuído nos trabalhos realizados pelo local; todavia, como enfatizado por esse falta uma maior interação, visto que muitas vezes são projetos desfocados um dos outros.

É importante mencionar que para pleitear os recursos do PRONAT, os municípios devem apresentar suas propostas à Caixa Econômica Federal/CEF. Por conseguinte, é feita uma seleção da mesma pelo gestor responsável, onde se apresenta o plano de trabalho a ser efetivado, dando a devida atenção aos objetivos 
contemplados pela modalidade pretendida; por fim, é feita uma análise preliminar da viabilidade de tal proposta pela instituição bancária.

Sendo assim, é necessário que o projeto conste no plano territorial, que por sua vez é apresentado à SDT para verificar a possibilidade do financiamento. Essa secretaria é a responsável pelo encaminhamento para a CEF, o agente financeiro responsável por acompanhar a implantação e a gestão dos projetos territoriais aprovados.

A seguir serão analisados os projetos territoriais que mais se destacam no local desde o ano de 2003 até 2008. É importante mencionar que existem vários casos em que um grande projeto foi subdividido em vários planos de trabalhos para viabilizar a contratação de obras, bens e serviços. Em sua maioria, são planos que não foram na totalidade efetivados, estando ainda em pauta.

\subsection{PROJETO: NUTRIVALE - DESPOLPADORA DE FRUTAS - PERSPECTIVA DE DESENVOLVIMENTO SUSTENTÁVEL PARA O VALE DO RIBEIRA}

Foi a partir de 2003 que as comunidades reivindicaram pela necessidade de uma despolpadora. De início, foi preciso encontrar um terreno para construir a unidade, o qual foi fornecido pela prefeitura. Porém, quando recebida a documentação do terreno os responsáveis pelo projeto viram que não seria permitido construí-la no local sugerido; posterior a isso, tiveram acesso a outro terreno, "só nisso foram mais de dois anos", de acordo com a gerente territorial do Vale do Ribeira.

De acordo com a mesma as dificuldades que permeiam a construção de um projeto para o território são múltiplas, muitas vezes "demora anos e anos para se concretizar um"; nesses casos, os recursos ficam retidos pela CEF rendendo juros, renovando os projetos quando necessário.

A despolpadora ainda não está instalada, o projeto esta em licitação na CEF; entretanto, devido a todo o ritual burocrático que há dentro dessa instituição bancária, a entrevistada acredita que "ainda vá um ano, um ano e meio para ser licitado", e assim serem liberados os equipamentos para a construção da unidade. 


\subsection{PROJETO: TELECENTROS E VÍDEO SALAS RURAIS}

Iniciado em 2004 o projeto pretendia promover a inclusão social e digital com o acesso a serviços de internet via satélite para atender aos agricultores familiares, por meio da implantação de telecentros e vídeo salas nas comunidades rurais. $\mathrm{O}$ intuito era suprir necessidades que foram levantadas pelo fórum do território de 2009, dentre algumas prioridades estava à criação de políticas públicas voltadas para o acesso aos meios de comunicação, educação e lazer.

$\mathrm{Na}$ atualidade a prefeitura proponente do projeto, localizada em Tunas do Paraná, esta com os equipamentos disponíveis para a montagem dos telecentros; porém, nem todos os municípios designaram um responsável para ir ao local retirálos. No fórum de 2009 constatou-se a necessidade de que cada município faça uma listagem dos materiais já adquiridos, sinalizando o que falta para esta parte do projeto ser concluída.

Há ainda outro impasse, os telecentros demandam um custo mensal para manutenção, sendo que esse é de responsabilidade das prefeituras. Dessa forma, é necessário que cada uma das prefeituras adquira ao menos o pacote mínimo solicitado para esta manutenção; somente assim, a CEF irá liberar o restante do recurso.

É importante frisar que se apenas uma não aderir ao pacote o recurso não será liberado; com relação a isso, o prefeito de Itaperuçu no fórum de 2009 mencionou que a prefeitura do município não dispõe de orçamento. Nesse projeto é urgente que haja um acordo por parte de todos, para não ocorrer à devolução do recurso ao ministério, tal como em outros projetos não efetivados até o final.

De fato, a instalação de telecentros e vídeos salas rurais é um modo de incluir socialmente as comunidades, todavia os municípios do território apresentam indicadores sociais e econômicos baixíssimos em comparação ao Estado do Paraná; questiona-se assim esse tipo de projeto, visto que há medidas mais urgentes a serem adotadas, tais como investimentos em habitação e saúde por exemplo.

Para a gerente territorial da EMATER o projeto está estruturado de forma positiva, o que esbarra sua efetivação é a dificuldade imposta pelos prefeitos, a exemplo de Itaperuçu; somado a isso, equipamentos de internet geralmente não são 
baratos, e "para o meio rural são ainda mais caros". De acordo com a entrevistada, tem-se já o acesso à informática, "a idéia já está posta, o que falta mesmo é a obra”. Projeto: Fortalecendo a agricultura familiar com o apoio de uma assistência técnica e extensão rural pública diferenciada para o território do Vale do Ribeira

A EMATER tem como foco de atuação o acompanhamento técnico e a extensão rural às comunidades do território; porém, como exposto pelo articulador a questão do acompanhamento técnico é "ainda muito frágil”.

Observou-se no fórum de 2009 que há dois pontos a serem superados para que de fato haja uma assistência técnica e extensão rural satisfatória; os técnicos da EMATER apesar do bom preparo para as atribuições que lhes são repassadas deveriam ser melhores instruídos para os trabalhos com as comunidades.

Há ainda um número insuficiente de técnicos para atender essas comunidades, um total de onze para o território. De acordo com o articulador o serviço é de boa qualidade; porém, "não dá conta do desafio proposto para o desenvolvimento do território".

A gerente territorial da EMATER complementa que essa assistência acaba sendo um tanto quanto pontual, "o mais importante e valioso é levar a informação das políticas públicas às comunidades distantes, priorizamos trabalhar com a inclusão social, você precisa disso, daquilo". Neste sentido estimulam ao máximo a organização das comunidades, para que essas tenham uma voz ativa na solicitação das políticas públicas, consolidando de fato uma assistência técnica para o território ao invés de focos de atuações.

\subsection{O PROJETO VOLTADO À LINHA DE LEITE PARA O VALE DO RIBEIRA}

Há um contínuo esforço por parte da maioria das instituições para que os municípios se desenvolvam de forma mais adequada e assim obtenham condições para se inserirem como produtores no Estado do Paraná; todavia, a conquista desses resultados é um desafio.

De acordo com o articulador do território a produção de leite em Adrianópolis apresenta grande sucesso, demonstrando que apesar da topografia local, este tipo de produção pode vir a obter êxito se bem estruturada em termos de serviços e informações adequadas aos agricultores familiares. 
Segundo informações obtidas no último fórum, é possível viabilizar o projeto para as merendas escolares; porém, há a necessidade dos produtos dos agricultores familiares serem certificados. De acordo com um dos atores sociais presente no fórum a "agricultura até então está repassando seus alimentos de forma 'clandestina' como se fosse um 'fora da lei'. Já foram iniciadas as medidas para solucionar este problema, sendo repassados aos agricultores como deve ser feito para obterem a certificação.

Há ainda dois outros desafios, a aquisição de quatro veículos e rádios amadores para o território. Os carros foram adquiridos; porém, os municípios em conjunto devem decidir como será feita a distribuição. Já os rádios amadores se tornam necessários para possibilitar a comunicação entre os agricultores, visto que muitos não têm acesso a aparelhos de celular; todavia, como mencionado pela gerente territorial as prefeituras ainda não fizeram a licitação do pedido.

Projetos referentes ao ano de 2008

Os planos de trabalhos elaborados para 2008 são respectivamente dois: a "Organização e comercialização solidária dos produtos dos agricultores familiares e quilombolas"; e o segundo, destinado para a "Regularização fundiária de imóveis rurais de agricultores familiares do território". Neste último, pretende-se adquirir um veículo tipo camionete e promover seminários sobre esse tipo de regularização, com o intuito de elaborar diagnósticos produtivos, produzir mapas municipais e publicações informativas.

De acordo com a gerente territorial da EMATER, o projeto para a regularização fundiária ainda não foi efetivado, objetiva-se utilizar o recurso de maneira estruturante, servindo de base para a elaboração de projetos futuros. Porém, há uma problemática muito séria para a regularização das comunidades, além do custo extremamente elevado, cerca de cinco mil reais em média, muitas das documentações para efetivar este processo esta no Estado de São Paulo, o que dificulta o acesso às informações.

Os trabalhos realizados com as comunidades quilombolas foram ressaltados pela entrevistada. As rodovias, por exemplo, apesar de ainda necessitarem de investimentos tiveram certo avanço; entretanto, o acesso as comunidades é ainda um desafio; existem treze quilombolas que se localizam a $80 \mathrm{~km}$ de distância da sede do município de Adrianópolis. 
É muito problemático quando o assunto se refere ao translado de populações entre os municípios, o recurso para melhoria das estradas existe; porém não será suficiente, há pelo menos cerca de $900 \mathrm{~km}$ de estradas internas que interligam os sete municípios.

A gerente territorial da EMATER menciona que há comunidades quilombolas que distam $60 \mathrm{~km}$ da sede do município de Doutor Ulysses, sendo que há crianças nesses locais que ao ir à escola simplesmente viajam $120 \mathrm{~km}$ todos os dias da comunidade à sede e enfrentam ainda $4 \mathrm{~km}$ de reflorestamento até suas casas "isto é um absurdo, gente estamos próximo de Curitiba! É preciso que se leve em conta as reais necessidades dessas populações do território".

Em suma, compreende-se que a multidimensionalidade amplamente difundida pelo PRONAT não se cumpre na prática. Ao contrário, os projetos territoriais, em sua maioria, são desconexos uns dos outros e não vão de encontro ao proposto pelo desenvolvimento territorial rural. A análise desses projetos faz crer que há um nítido desafio para a promoção desse tipo de desenvolvimento, diversos são os exemplos que ilustram esse quadro.

\section{OS DESAFIOS PARA EFETIVAR O DESENVOLVIMENTO TERRITORIAL}

As dificuldades de se efetivar o desenvolvimento do território são múltiplas. Apesar do grande esforço por parte dos atores sociais, há a falta de um recurso humano qualificado para trabalhar na elaboração de projetos futuros. O principal, a construção das obras, não está sendo efetivado, são adquiridos tão somente equipamentos. De acordo com o entrevistado A da SEAB:

\footnotetext{
Temos um esforço grande de utilizar aquilo que é disponibilizado, mas lógico existe uma série de dificuldades quando você parte para a questão da execução, a própria exigência para contração, documentação, feita geralmente por prefeituras, às vezes você tem dificuldade na documentação, certidões uma série de coisas, então acontece às vezes de perder recurso, aprova a utilização do recurso, mas no decorrer da contratação termina perdendo o recurso, algumas vezes, por necessidades burocráticas que não são cumpridas.
}

Falta um maior diálogo por parte das instituições que atuam no território "muitas vezes uma está trabalhando em algo semelhante à outra e nem sabem" como mencionado pelo entrevistado A. Fora isto, a dependência desses atores 
sociais, de instituições como a CEF, por exemplo, é um fato que não pode ser negligenciado, muitas vezes esta impede a liberação dos recursos devido a todo o ritual burocrático existente dentro da instituição.

Convêm mencionar sobre outro desafio, o monitoramento. O intuito neste é diagnosticar as debilidades, os avanços e como vem se dando o funcionamento e a execução dos projetos para o território, para assim propor medidas corretivas caso sejam necessárias (MDA, 2006, p. 24).

Conforme informações fornecidas pelo entrevistado $A$ da SEAB há o programa de monitoramento no território numa fase ainda embrionária. De acordo com o mesmo até o momento não havia um sistema de controle de uso do recurso satisfatório. Como solução o Instituto Paranaense de Desenvolvimento Econômico e Social (IPARDES) irá elaborar um sistema de controle dos contratos feitos no território, mas "realmente o controle e a fiscalização realizados até agora, sinceramente deixam a desejar".

Ainda em fase de construção o sistema será elaborado com base em um banco de dados com todos os projetos aprovados pelo PRONAT desde 2003 em cada um dos municípios, especificando quais obras foram realizadas com o uso do recurso.

De acordo com o entrevistado B a finalidade é verificar se o objetivo do projeto foi alcançado, para diagnosticar se realmente provocou mudanças positivas aos municípios, servindo como "uma ferramenta de avaliação de política pública". 0 monitoramente é considerado bastante inovador para o respectivo entrevistado, uma vez que permitirá avaliar o porquê determinado projeto não obteve êxito, servindo de base para a elaboração de outros projetos.

Porém, políticas públicas para o meio rural necessitam de alguns cuidados, principalmente quando se referem às políticas descentralizadas como é o caso do PRONAT. Como bem enfatizado pelos entrevistados A e B da SEAB o processo de dar atribuições tanto às esferas federais, estaduais e municipais precisa ser melhorado.

Retomando Abramovay (2000), este já expunha que na maioria das vezes os municípios rurais são as unidades menos adequadas para gerir as relações necessárias ao desenvolvimento territorial. Como exposto pelo autor, não se trata de desprezar as possibilidades de ação que há nessa esfera política administrativa, 
mas sim reconhecer que as esferas municipais perpassam por uma característica que Ihe é peculiar, a falta de preparação para a gestão de recursos públicos de forma descentralizada.

Em sua maioria, esses municípios apresentam um forte grau de poder político, geralmente definido na figura do prefeito, que reproduz certas relações de natureza clientelista com determinados segmentos da população bem definidos; há a manutenção pelo território de certos esquemas convencionais, tais como o favorecimento e a retribuição por meio de votos. Sendo assim, é preciso repensar as atribuições dadas à esfera municipal, ainda mais quando se tratam de municípios que possuem este tipo de dominação.

De fato o local não tem usufruído de um desenvolvimento territorial. Questiona-se esse tipo de desenvolvimento; uma vez que o discurso proposto pelas instâncias governamentais não se configura na realidade, uma "tentativa planificada racionalmente de melhorar a qualidade de vida da população" (MONTENEGRO GÓMEZ, 2007, p. 39).

Observa-se ainda que o aumento da qualidade de vida proposto pelo documento Referências... (2005) e tantos outros elaborados pelo MDA e SDT não é uma realidade do local. Muito pelo contrário, está-se diante de um território que apresenta além de dificuldades de todo o tipo, uma população com problemas sociais e econômicos que não podem ser relegados a um segundo plano.

Nota-se também que os projetos territoriais não vão de encontro às reais necessidades de infra-estruturas mencionadas pelo Plano... (2005) tais como: estradas, habitação, escolas, hospitais, saneamento básico, dentre diversas outras; o que deve ser incentivado de forma mais contundente, para que os municípios obtenham de fato melhorias sociais e econômicas.

Sendo assim, concorda-se com Abramovay (2000) quando este referencia que os projetos para o meio rural tendem a responder geralmente a necessidades localizadas, não sendo um plano elaborado por um universo de forças realmente diversificadas e oriundas da sociedade civil. 


\section{CONSIDERAÇÕES FINAIS}

Conclui-se que mesmo em meio às dificuldades, os atores sociais do Vale do Ribeira tem tido grande esforço para que a população participe na elaboração dos projetos territoriais demandados ao local; porém, essa participação é ainda incipiente, na maioria das vezes a construção desses projetos é realizada por um grupo reduzido de indivíduos.

Os percalços que os atores sociais perpassam até obterem os recursos do PRONAT são múltiplos, sendo que um deles se destaca. Trata-se da relação do território com a CEF, o agente financeiro responsável pelas tarefas de acompanhar, implementar e estabelecer a gestão dos projetos aprovados.

É preciso analisar com ressalva até que ponto este agente é o mais adequado para gerir tarefas essenciais ao território, uma vez que se trata de uma instituição eminentemente urbana. Mesmo possuindo um corpo técnico apropriado para desempenhar as funções que Ihes são atribuídas, na realidade os técnicos desconhecem as verdadeiras necessidades das comunidades rurais.

Constata-se que no local grande parte de seus projetos estão "parados", as dificuldades para serem efetivados são variadas; seja por impasses jurídicos na CEF, ou por problemas dentro das próprias prefeituras. Ambos acabam sendo os responsáveis pela dificuldade de se mobilizar mais recursos, materiais e financeiros.

Há ainda um nítido problema, a relação dos atores sociais com os prefeitos dos municípios; observa-se que os últimos desconsideram a real necessidade de se exercer um trabalho em conjunto. Algo de grande valia seria existir uma maior articulação das relações a nível municipal, um caminho para o território usufruir de melhorias sociais e econômicas.

As medidas adotadas em termos de políticas públicas não configuram um verdadeiro programa de desenvolvimento. No caso específico do PRONAT; não há de fato um programa em prol do desenvolvimento territorial, que permita visualizar seus objetivos, finalidades de execução de forma clara, ou seja, todos os requisitos necessários de um programa institucionalizado em lei.

Correlacionado a isso, além dos recursos serem insuficientes são aplicados de uma forma não integrada; uma despolpadora ainda não efetivada, telecentros e 
vídeo salas rurais inoperantes, assistência técnica insuficiente e projetos voltados à linha de leite com desafios a serem superados.

Caso esses investimentos não sejam melhores estruturados, jamais uma população como a do Vale do Ribeira será incluída socialmente. Uma alternativa é fortalecer as relações entre a sociedade civil e as instituições que atuam pelo território, capacitando todos os envolvidos, resultando de fato em um projeto integrado.

As medidas estabelecidas pelo PRONAT são um grande desafio para aprimorar o desenvolvimento territorial rural. Uma política pública adequada para cada localidade seria essencial, planejando-a de forma a tomar os devidos cuidados para suprir as reais necessidades das comunidades rurais.

\section{REFERÊNCIAS}

ABRAMOVAY, R. O capital social dos territórios: repensando o desenvolvimento rural. Economia aplicada, São Paulo, v. 4, n. 2, abr./jun. 2000.

BEDIN. O. L. Participação dos agricultores familiares no programa PRONAF modalidade infra-estrutura: um estudo de caso no município de Tupãssi - PR. Dissertação (Mestrado em Engenharia de Produção), Universidade Federal de Santa Catarina, Florianópolis, 2005. 1 CD-ROM.

FERNANDES, B. M. Entrando nos territórios do Território. Presidente Prudente: NERA, 2008.

HESPANHOL. A. N. O desenvolvimento do campo no Brasil. In: FERNANDES, B. M.; MARQUES, M. I. M.; SUZUKI, J. C. (orgs). Geografia agrária: teoria e poder. São Paulo: Expressão popular, 2007. p. 271- 287.

INSTITUTO PARANAENSE DE DESENVOLVIMENTO ECONÔMICO E SOCIAL. Vale do Ribeira: referências da Dinâmica Regional. Curitiba, 2003. Disponível em $<$ http://www.ipardes.gov.br/publicacoes/publicacoes_estudos_novo. php >. Acesso em: 10/1/2010. 22 p.

MINISTÉRIO DO DESENVOLVIMENTO AGRÁRIO. Plano territorial de desenvolvimento rural sustentável guia para o planejamento. Brasília: SDT/MDA, 2005. Disponível em: < http://sistemas.mda.gov.br/sdt/index. php?sccid=482 >. Acesso em: 21/6/2009. 
. Referências para uma Estratégia de Desenvolvimento Rural Sustentável no Brasil. Brasília: SDT/MDA, 2005. Disponível em: <http://sistemas.mda.gov.br/sdt/index. php?sccid=482 >. Acesso em: 13/102009.

Referências para a gestão social dos territórios rurais - guia para a Organização Social. Brasília: SDT/MDA, 2006. Disponível em: <http://sistemas.mda.gov.br/sdt/index. php?sccid=482 >. Acesso em: 13/10/2009.

MONTENEGRO GÓMEZ, J. R. Desenvolvimento em (des) construção: provocações e questões sobre desenvolvimento e geografia. In: FERNANDES, B. M.; MARQUES,

M. I. M.; SUZUKI, J. C. (orgs). Geografia agrária: teoria e poder. São Paulo: Expressão popular, 2007. p. 39-53.

Desenvolvimento em (des) construção narrativas escalares sobre desenvolvimento territorial rural. $440 \mathrm{f}$. Tese (Doutorado em Geografia). Universidade Estadual Paulista. Presidente Prudente, 2006. Disponível em: < http://www4.fct.unesp.br/ceget/Jorge/jorgetese.pdf >. Acesso em: 24/2/2009.

SCHNEIDER, S. A abordagem territorial do desenvolvimento rural e suas articulações externas. SCIELO, Porto Alegre, n. 11, p. 88-125, jan/jun 2004. Disponível em: < http://www.scielo.br/pdf/soc/n11/n11a06.pdf >. Acesso em: $24 / 4 / 2009$.

SOUZA, M. J. L. de. O território: sobre espaço e poder, autonomia e desenvolvimento. In: CASTRO, I. E, GOMES, P. C.; CORRÊA, R. L. (ed.). Geografia: Conceitos e Temas. Rio de Janeiro: Bertrand, 2003, p. 77-116.

VEIGA, J. E. da. Desenvolvimento Territorial do Brasil: do entulho varguista ao zoneamento ecológico-econômico. In: XXIX Encontro Nacional de Economia, Salvador, $2001 . \quad$ Disponível em http://www.anpec.org.br/encontro2001/artigos/200105079.pdf >. Acesso em: 20/3/2009. 